Landslides (2009) 6:375

DOI 10.1007/s10346-009-0174-3

Received: 21 September 2009

Accepted: 21 September 2009

Published online: 15 October 2009

(c) Springer-Verlag 2009
Baolin Wang

\section{K. Sassa, H. Fukuoka, F. Wang and G. Wang (eds): Progress in landslide science}

\author{
Springer-Verlag, 2007, ISBN 978-3-540-70964-0
}

This book compiles findings from recent research works on landslides. The book consists of 26 chapters that are grouped into four parts: I-Progress in landslide science, II-Landslide dynamics, III-Landslide monitoring and IV_-Landslide risk assessment. Each chapter is authored by one or more experts specialised in the subject area. The contributions from an international group of 50 specialists allowed the book to cover a relatively broad range of topics, as well as geographically diverse areas.

The book starts with an introductory chapter in part I that presents issues facing the world and efforts being made to deal with such issues at an international level. There are four subsequent chapters in part I covering (1) an overview of landslide problems and their primary causes in Britain, (2) various mechanisms related to slow active landslides in clay with case histories, (3) behaviour of various types of rapid landslides and (4) techniques for modelling debris flows.

The second part consists of ten chapters, with the majority of the chapters covering shear testing, physical modelling and discussions about shear behaviour of several types of materials. It also discusses effects of pore water pressure, dynamic loading, fragmentation and dynamics of particle flows.

The third part, with four chapters, focuses on landslide monitoring using conventional and emerging monitoring techniques, e.g. strain gauges, extensometers, airborne light detection and ranging (LiDAR) and remote sensing with satellite technologies. The landslide monitoring techniques are presented mostly in the form of case histories supported by other types of studies, e.g. numerical modelling and laboratory testing.

The last part (part IV) of the book consists of seven chapters with topics related to slope failure mechanisms and landslide risk assessment. The coverage extends from methods of evaluating debris flow characteristics, hazards, risks to mitigation and remediation measures. Although chapters 22 and 23 might be better suited to part II, those two chapters discuss landslide failure mechanisms from experimental and numerical analysis view points that are useful for landslide risk assessments. Part IV of the book ends with a chapter describing a four-step method to quantify losses associated with debris flows. The step-by-step approach evaluating probability and extent of events, economic damage and loss of lives is demonstrated with examples.

To further extend what is introduced in chapter 1 , there are two appendices at the end of the book that include further information about some general issues related to landslides and how the world organisations are working together and dealing with those issues.

This 378 page book is printed in colour that makes the details in figures easy to recognise. Most of the images (349 out of 431) are in colour. This can be important for landslide books to convey information effectively. Readers may find that this hard-covered book is published in a high quality of the familiar Springer standard.

The editors are congratulated for their great effort on getting this multi-author book well organised and edited. A minor inconvenience readers may encounter is figuring out the meanings of the asterisks following some authors' names of the multi-author chapters. Careful readers may find that a footnote for those asterisks is provided on the first page of chapter 2 where the asterisk appears the first time, which is logical, but it would have been better noted in a different way or with no footnote at all. However, this minor inconvenience is overcome by a handy list of contributors with contact information provided at the beginning of the book.

Landslide researchers and practitioners may find this book useful for updating and validating their knowledge. It is recommended to keep as a reference book for landslide specialists.

[ESS Contribution number: 20090199]

\section{B. Wang ( $)$}

Natural Resources Canada,

Ottawa, Ontario, Canada

e-mail: bwang@nrcan.gc.ca 